\title{
The Uncertain Lifetime and the Timing of Human Capital Investment *
}

\author{
Sebnem Kalemli - Ozcan ${ }^{\dagger}$ \\ University of Houston and NBER
}

May 2006

\begin{abstract}
I examine the effects of mortality decline on fertility and human capital investment decision of parents taking into account the uncertainty about child survival. The existence of such uncertainty implies that in principle parents can choose between two different strategies regarding the timing of the educational investment. Education may be provided before or after uncertainty about child survival is realized. I propose a model, where parents decide on their fertility before the uncertainty is realized but they choose to invest only in human capital of their surviving children. The model implies a positive relationship between mortality and fertility and a negative one between mortality and educational investment. It has been argued elsewhere that since in reality most of the mortality decline occurred in infancy it should not affect the human capital investment decision, which comes later in life. Thus increased survival chances should not promote growth by raising the human capital investment. This paper argues the contrary and proposes a mechanism where mortality decline at any age before the teen years can promote growth by raising human capital investment regardless of the timing of the educational investment.
\end{abstract}

JEL Classification: O40, I12, J11, J13

Keywords: Mortality, Human Capital Investment, Survival Probability, Economic Growth

${ }^{*}$ I thank, Alessandro Cigno, David Weil, Herschel Grossman and two anonymous referees for valuable comments and suggestions.

${ }^{\dagger}$ Department of Economics, University of Houston, Houston, TX, 77204. Tel: 713-7433824. Fax: 713-7433798. e-mail: Sebnem.Kalemli-Ozcan@mail.uh.edu 


\section{Introduction}

One of the distinguishing features of the past century is the decline in mortality rates. Figure 1 plots the probability of survival by age for Sweden since 1780. Although the likelihood of survival for all ages increased tremendously between 1780 and 1990, the most significant reduction in mortality was realized at infancy and childhood. In 1780, in Sweden, a newborn child had a $60 \%$ chance of living to age 20. By 1930, this figure had risen to $90 \%$. These patterns can also be seen in the historical data for the other developed countries. The contemporary data for the less developed regions (LDCs) of the world show that infant and child mortality fell approximately $60 \%$ between 1950 and $1990 .{ }^{1}$

The declines in mortality rates have been followed by a decline in the fertility rate and an increase in the educational investment. ${ }^{2}$ In a world in which parents are prudent in the face of uncertainty a reduction in mortality is important since mortality declines over time have not only increased the expected length of a child's life span (mean age of death), but also significantly lowered their variability (variance of age of death). As a result parents with precautionary motives tend to produce fewer children. At the same time higher life span with lower variability implies a higher rate of return, hence declining child and youth mortality provides an important incentive to increase investment in human capital of each child. ${ }^{3}$ The decline in fertility rates and the increase in human capital investment will promote economic growth.

Existing models of endogenous fertility and human capital investment, if they allow for mortality at all, do so in the context of certainty. ${ }^{4}$ The model in this paper is an extension of Kalemli-Ozcan (2003), which allows for uncertainty about child survival. Kalemli-Ozcan (2003) shows that if the marginal utility of a surviving child is convex in the number of survivors, then there will be a precautionary

\footnotetext{
${ }^{1}$ See United Nations (1999).

${ }^{2}$ Historical and contemporary data show that mortality decline preceded the fertility decline. This whole phenomenon is known as "demographic transition". Eckstein et al. (1998), in a study of Swedish fertility dynamics, show that the reduction in infant and child mortality is the most important factor explaining the fertility decline, while increases in the real wages can explain less than one-third of the fertility decline. In developed countries, fertility decline, which began by the end of the nineteenth century, was completed by World War II. During this period, the total fertility rate (TFR) declined from 5 children to 2.5 children. In the developing world, the fertility transition started around the $1950 \mathrm{~s}$, and over the past forty years TFR declined from 6 children to 3 children. The data on educational attainment show that the average number of years of schooling in England rose from 2.3 for the cohorts born between 1801 and 1805 to 9.1 for the cohorts born between 1897 and 1906. It rose even further to 14 for the 1974-1992 cohorts. In LDCs, gross secondary school enrollment increased from $17.1 \%$ in 1960 to $46.9 \%$ in 1990. See Livi-Bacci (1997), United Nations (1999), and Matthews, Feinstein, and Odling-Smee (1982).

${ }^{3}$ Ram and Schultz (1979) argue that improvements in mortality are an important incentive to increase investment in education at any age, and that the post-war experience of India was consistent with this incentive effect being significant. Meltzer (1992) argues that the elasticity of enrollment with respect to rate of return is sufficiently large that mortalityinduced increases in returns could indeed explain large movements in enrollment. Kalemli-Ozcan et al. (2000) show that 1 percent reduction in mortality leads to 1 percent increase in schooling.

${ }^{4}$ See Becker and Barro (1988), Boldrin and Jones (2002), Chakraborty (2004), Ehrlich and Lui (1991), Meltzer (1992), Soares (2004), and Strulik $(2003,2004)$. Note that these models consider either utility from children or utility from average number of surviving children, ignoring uncertainty about child survival. Also only a few of these models endogenize human capital investment together with fertility. See Lorentzen et al. (2004) for an excellent review of the literature on mortality and fertility.
} 
demand for children. As the mortality rate and thus uncertainty falls, this precautionary demand and hence "hoarding" of children decreases, freeing up previously wasted resources for the human capital investment. ${ }^{5}$ However, Kalemli-Ozcan (2003) assumes that parents' fertility and educational investment decisions are simultaneous and thus they invest in human capital of their children before the uncertainty about their survival is resolved. Galor (2005) argues that this formulation is implausible in terms of the cost of investing in the children that die. The more realistic scenario would be to invest in education after uncertainty about mortality is realized.

In this paper, I show that mortality decline causes educational investment to increase even if parents provide it only for their surviving children. The model establishes that as a result of an exogenous decline in mortality, parents decrease their precautionary demand for children, freeing up previously wasted resources for investment in surviving children. It has been argued extensively in the literature that since in the data most of the mortality decline occurred in infancy, mortality should not be a factor for human capital investment decision, which comes later in life. Thus increased survival chances should not promote growth by raising human capital investment. One answer to this criticism is that mortality declines, which are relevant for the return to human capital investments, are not so small because they spread over a much longer interval than infant mortality. ${ }^{6}$ However this will not be a complete explanation since we still do not know the answer to the following question: what is the channel through which declining mortality causes increased education? This paper proposes one possible channel where mortality decline at any age before the teen years can promote growth by raising human capital investment regardless of the timing of the educational investment. For the results in the paper it doesn't have to be the case that declines in infant mortality are much bigger than declines in age 10-15 mortality or vice versa. On the contrary given the key mechanism is the decrease in the precautionary demand for children as a result of the mortality decline, child mortality beyond infancy (age 1) is important for the results since infant deaths can be replaced.

The model is also consistent with the stylized facts of the demographic transition. At the start of the demographic transition mortality rates decline, and are then followed by a decline in fertility rates (children born per woman). Eventually the decline in fertility rates overwhelms the decline in mortality rates, causing an inverted U-shaped pattern for net fertility (the number of children reaching adulthood), and hence for population growth. Galor (2005) argues that the cause of the reduction in net fertility is most relevant from an economic point of view. He claims that the decline in the number

\footnotetext{
${ }^{5}$ See also Sah (1991), Wolpin (1997), Cigno (1998), and Doepke (2004) who also consider uncertainty about child survival. Doepke (2004) shows that the insurance effect (hoarding) will disappear when replacement for the death children is allowed. However, empirical micro studies estimate the replacement effect to be less than 1 , mostly around 0.2 as argued by Schultz (1997). Schultz (1997) shows a positive effect of child mortality on fertility using panel data from a set of developing countries and argues that this must be due to the insurance effect since the estimated replacement effect is so small.

${ }^{6}$ Note that although the mortality changes around ages 10-15 are not as big as the ones around infancy, they are still pretty large. In Sweden probability of a child at age 10 dying before age 15 declined $75 \%$ between 1800 and 1930 . Around 1800, 5200 children die between ages 5 and 15 out of 100000 birth, whereas around 1930 only 400 die out of 100000 birth.
} 
of surviving offspring that was observed during the demographic transition is unlikely to follow from a mortality decline. ${ }^{7}$ The model presented here is consistent with the hump-shaped relation between the number of survivors and the survival probability, implying mortality decline can be one of the mechanisms that triggers the demographic transition. ${ }^{8}$

The rest of the paper is structured as follows. Section 2 presents the model. Section 3 performs a simple quantitative exercise. Section 4 concludes.

\section{The Model}

Consider an OLG model, where individuals within a generation have identical preferences. Members of generation $t$ live for two periods: in the first period of life, $(t-1)$, individuals consume a fraction of their parent's unit time endowment, and in the second period of life they decide on their consumption, fertility and children's education. The preferences of the altruistic member of generation $t$ are defined over second period's consumption, $C_{t}$, and the future income of the survivors, $N_{t} w_{t+1} h_{t+1}$, where $N_{t}$ is the number of survivors, $w_{t+1}$ is the future wage of a survivor per unit of human capital and $h_{t+1}$ is the human capital of a survivor. The utility function for a member of generation $t$ is

$$
U_{t}=\gamma \ln \left[C_{t}\right]+(1-\gamma) \ln \left[N_{t} w_{t+1} h_{t+1}\right] .
$$

Human capital production is given by

$$
h_{t+1}=e_{t}^{\beta} h_{t}, \quad 0<\beta<1,
$$

where $e_{t}$ is the education level of a child and $h_{t}$ is the level of parental human capital.

\footnotetext{
${ }^{7}$ Galor (2005) argues that mortality decline would have led to a reduction in the number of surviving offspring if the following set of implausible conditions would be met: (i) There exists a significant precautionary demand for children, i.e., individuals are significantly risk averse with respect to their expected number of surviving offspring and they hold a buffer stock of children in a high mortality environment. (ii) Risk aversion with respect to consumption is smaller than risk aversion with respect to fertility. (iii) Sequential fertility (i.e., replacement of non-surviving children) is modest. (iv) Previously wasted resources via investing in the human capital of every new born (who might die) would not cause an increase in fertility as a result of a decline in mortality. I would argue that only one out of these four assumptions is needed to have an effect of mortality decline on the number of surviving children and that is the absence of sequential fertility, i.e., the condition (iii). However, this is not an implausible assumption given the size of the empirical estimates of the replacement effect, which are around 0.2. One also needs the existence of the precautionary demand, i.e., positive third derivative of the utility function but one does not need the precautionary demand to be significant or high. So the condition i) is not needed. The condition (ii) is also not needed since both the current paper and Kalemli-Ozcan (2002) use log utility, which implies same degree of risk aversion for both consumption and fertility. The current paper shows that condition (iv) is also not needed.

${ }^{8}$ See also Sah (1991) and Kalemli-Ozcan (2002) for a similar result. There are other models that are in the spirit of Barro-Becker world where fertility might be positively related to mortality but net fertility is linearly and negatively related to mortality, which is inconsistent with the data since the relationship between net fertility and life expectancy is hump-shaped. Among these models are Doepke (2004) and Boldrin and Jones (2002). Cigno (1998) and Strulik (2003) show that there is a negative relationship between mortality and total fertility when mortality is high and a positive relationship when mortality is low.
} 
Households choose the number of children, $n_{t}$, which is a one-time fertility decision in an uncertain environment. They also choose the amount of education to give to each surviving child, $e_{t}$. These choices are subject to a constraint on the total amount of time, which is unity. Assuming a fixed time cost, $v \in(0,1)$, for every child, the time left for the household for work to earn a wage income, is $1-v n_{t}-e_{t} N_{t}$. Thus the intertemporal budget constraint for consumption is given by;

$$
C_{t}=w_{t} h_{t}\left(1-v n_{t}-e_{t} N_{t}\right)
$$

In this setup, the second period can be thought of as a long period where parents first decide on how many children to have and after the survivors are realized choose the amount of human capital investment. It is clear that the problem can be solved in two steps. Since uncertainty will be completely resolved before the human capital investment decision stage, fertility and education decisions can be solved separately. ${ }^{9}$

\subsection{Benchmark Case: Human Capital Investment in Surviving Children Under Certainty}

To show the importance of uncertainty, we first examine a benchmark case with certainty. Of course, the two step nature of the problem is not a factor under certainty and $N_{t}$ will be taken as equal to the expected number of survivors, that is, $n_{t} q$, where $q$ denotes the survival probability. ${ }^{10}$

Substituting the budget constraint in the utility function, the optimization problem of a member of generation $t$ is

$$
\left\{n_{t}, e_{t}\right\}=\operatorname{argmax}\left\{\gamma \ln \left[w_{t} h_{t}\left(1-v n_{t}-e_{t} n_{t} q\right)\right]+(1-\gamma) \ln \left[n_{t} q w_{t+1} h_{t+1}\right]\right\}
$$

subject to: $\left(n_{t}, e_{t}\right) \geq 0$.

The optimization with respect to $n_{t}$ implies

$$
n_{t}\left(e_{t}\right)=\frac{1-\gamma}{v+e_{t} q}
$$

The optimization with respect to $e_{t}$ implies

$$
e_{t}\left(n_{t}\right)=\frac{\beta(1-\gamma)}{(\beta(1-\gamma)+\gamma)} \frac{\left(1-v n_{t}\right)}{n_{t} q}
$$

\footnotetext{
${ }^{9}$ If parents give education to every newborn child before the uncertainty about the survival is realized, each child will have a fixed cost and an education cost regardless of whether he or she dies, implying a budget constraint of the form $C_{t}=w_{t} h_{t}\left(1-v n_{t}-e_{t} n_{t}\right)$. This model is studied in Kalemli-Ozcan (2003). If education is given to each survivor after the uncertainty is realized then each child has a fixed cost but only survivors have an education cost, implying the budget constraint as given in equation (3).

${ }^{10}$ Note that child survival is independent across siblings.
} 
Solving two first order conditions simultaneously implies

$$
\begin{aligned}
n_{t}^{*} & =\frac{(1-\gamma)(1-\beta)}{v}, \\
e_{t}^{*} & =\frac{\beta v}{(1-\beta) q} .
\end{aligned}
$$

Proposition 1: If parents decide to invest in human capital of each surviving child under certainty (i.e., taking the number of survivors as equal to the expected number), an exogenous increase in the survival probability has no effect on the optimal amount of fertility, but it has a negative effect on the optimal amount of human capital investment.

$$
\begin{aligned}
& \frac{d n_{t}^{*}}{d q}=0, \forall q, \\
& \frac{d e_{t}^{*}}{d q}<0, \forall q .
\end{aligned}
$$

Proof: Follows directly from equation (7).

If the human capital investment is the engine for growth, this suggests that mortality decline is bad for economic growth! What is the intuition behind this result? Let me start with the fertility result, which follows from the fact that log utility implies unitary elastic demand for children with respect to their cost. With increased survival, the price of a surviving birth, $v / q$, declines, thus making the number of survivors relatively more desirable given the fact that children are normal goods. This price change has income and substitution effects. The income effect indicates that both consumption and the number of survivors will increase, which in turn implies that the number of children will rise. The substitution effect works in the opposite direction, meaning consumption will decline and the number of survivors will increase. With log utility the income and substitution effects balance out, so consumption and number of children are not affected by the increase in $q \cdot{ }^{11}$ Results will be worse with the CRRA utility function. With high elasticity of substitution, consumption decreases and number of children increases with an increase in $q$. This is a typical result from the literature since most of the literature uses a CRRA utility function. This result is inconsistent with the data in the long run. ${ }^{12}$

What about the negative effect of the survival probability on the educational investment. As argued above, with the increased survival, the fixed cost of producing a survivor, $v / q$, declines, implying an increase in the number of survivors. However, the relative price of an educated survivor also declines.

\footnotetext{
${ }^{11}$ The budget constraint implies $\left(C_{t}=w_{t} h_{t}\left(1-v n_{t}-e_{t} n_{t} q\right)\right)$ both consumption and the number of children does not change given the decline in $e_{t}$.

${ }^{12}$ Note that with a CRRA utility function, such as $\frac{C_{t}^{1-\sigma}}{1-\sigma}$, the parameter $\sigma$ is the inverse of intertemporal elasticity of substitution in consumption. Thus, the results $d C_{t} / d q<0$ and, $d n_{t} / d q>0$ require $\sigma<1$. This parameter restriction implies children have an elastic demand with respect to their cost.
} 
With high mortality parents must have two children and educate only one to have one educated survivor, but with low mortality parents can have one child and educate this child to have one educated survivor. Thus, parents want to produce more survivors but give less education to each, with a decline in the price of survivors. Thus, the optimum amount of education will decrease with an increase in $q$. The result is same under the CRRA utility function. ${ }^{1314}$

Considering uncertainty, as shown in the next section, introduces an additional effect that can dominate this negative effect of higher $q$ on $e_{t}$. The additional effect comes from the fact that under uncertainty fertility declines with increased survival probability, causing an overall positive effect on educational investment.

What about the effect of increased survival on the number of survivors?

Proposition 2: Under certainty, there is a positive effect of an increase in the survival probability on the expected number of survivors and hence on the population growth rate.

The population growth rate can be written as;

$$
\frac{L_{t+1}}{L_{t}}-1=E_{t}\left(N_{t}^{*}\right)-1=q n_{t}^{*}(q)-1,
$$

where $L_{t}$ is the size of the population at time $t .^{15}$

$$
\frac{d E\left(N_{t}^{*}\right)}{d q}=n_{t}^{*}=\frac{(1-\gamma)(1-\beta)}{v}>0 .
$$

Proof: This follows directly from the first part of equation (8).

This result is not consistent with the facts of demographic transition. During the transition population growth increases first (as a result of mortality decline) but then it declines since the decline in fertility surpasses the decline in mortality. The model outlined in the next section is consistent with these facts.

\subsection{Human Capital Investment in Surviving Children under Uncertainty}

As mentioned above, this problem can be solved with backwards induction in two steps since the uncertainty will be completely resolved before the human capital investment decision. First, I solve

\footnotetext{
${ }^{13}$ This is because this result depends on the change in the relative price and not on the change in the fixed price which will have income and substitution effects.

${ }^{14}$ If investment were given to all children (under certainty again) instead of only to the surviving children then the effect of increased survival on education will be zero (as shown in Kalemli-Ozcan, 2003). The reason is that when investment is given to all the children although the fixed cost of producing a survivor still declines, the relative price of an educated survivor does not change as oppose to when investment is only given to the surviving children as shown above. With high mortality, in order to have one educated survivor parents must have two children and provide the same amount of education to each. But if there is no mortality then parents can have one child and educate him or her and hence they can have one educated survivor. Thus, there is no point in changing the optimal amount of education with an increase in $q$ when education is provided for all the children instead of only for the surviving ones.

${ }^{15}$ Note that due to the law of large numbers there is no aggregate uncertainty even though there is individual uncertainty, and hence the population growth rate is $E_{t}\left(N_{t}\right)-1$.
} 
for the optimal amount of education, $e_{t}^{*}$, given the number of children and survivors. The second step is to evaluate $U_{t}\left(n_{t}, N_{t}, e_{t}=e_{t}^{*}\right)$ and maximize $E_{t}\left(U_{t}\right)$ with respect to $n_{t}$ under uncertainty.

\section{Step 1:}

Given that uncertainty is resolved, maximizing the utility with respect to $e_{t}$ for given $n_{t}$ and $N_{t}$ implies

$$
\left\{e_{t}\right\}=\operatorname{argmax}\left\{\gamma \ln \left[w_{t} h_{t}\left(1-v n_{t}-e_{t} N_{t}\right)\right]+(1-\gamma) \ln \left[N_{t} w_{t+1} h_{t+1}\right]\right\},
$$

subject to: $\left(e_{t}\right) \geq 0$, which in turn gives,

$$
e_{t}=e_{t}^{*}\left(n_{t}, N_{t}\right)=\frac{\beta(1-\gamma)}{(\beta(1-\gamma)+\gamma)} \frac{\left(1-v n_{t}\right)}{N_{t}} .
$$

Thus, the time spent on survivors is negatively related to the number of children, negatively related to the number of survivors and positively related to returns to human capital investment. Substituting $e_{t}$ into the utility function in equation (11) results in

$$
U_{t}\left(n_{t}, N_{t}\right)=\left\{\gamma \ln \left[\frac{\gamma h_{t}\left(1-v n_{t}\right)}{\gamma+\beta(1-\gamma)}\right]+(1-\gamma) \ln \left[\left(\frac{\beta(1-\gamma)}{\gamma+\beta(1-\gamma)}\right)^{\beta} h_{t}\left(1-v n_{t}\right)^{\beta} N_{t}^{(1-\beta)}\right]\right\}
$$

\section{Step 2:}

With uncertainty, $N_{t}$, the number of survivors, will be a random variable drawn from a binomial distribution. Thus, the probability that $N_{t}$ out of $n_{t}$ children to survive is given by the binomial distribution at time $(t)$;

$$
f\left(N_{t} ; n_{t}, q\right)=\left(\begin{array}{c}
n_{t} \\
N_{t}
\end{array}\right) q_{t}^{N}(1-q)^{n_{t}-N_{t}} \quad N_{t}=0,1, \ldots, n_{t} .
$$

Members of generation $t$ choose the number of children in order to maximize their expected utility as of time $(t)$,

$$
E_{t}^{t}\left(U_{t}^{t}\right)=\sum_{N_{t}=0}^{n_{t}}\left\{\gamma \ln \left[C_{t}^{t}\right]+(1-\gamma) \ln \left[N_{t} w_{t+1} h_{t+1}\right]\right\} f\left(N_{t} ; n_{t}, q\right) .
$$

This formulation implies that the number of children born and the number of surviving children are represented as nonnegative integers, which is a discrete representation. However one needs a continuous representation in order to perform comparative static analysis. Under certainty the number of survivors is taken equal to the mean, ignoring the random nature and hence the risk. To incorporate the risk and have a continuous representation I use the Delta Method and approximate the utility around the mean and the variance of the binomial distribution. This approach allows me to incorporate the variance, which is nothing but the risk effect, in a tractable way and have a continuous representation. 
By using the Delta Method and taking expectations, equations (13) and (15) can be combined as, ${ }^{16}$

$$
\begin{aligned}
\left\{n_{t}\right\} & =\operatorname{argmax}\left\{\gamma \ln \left[\frac{\gamma h_{t}\left(1-v n_{t}\right)}{\gamma+\beta(1-\gamma)}\right]\right. \\
& +(1-\gamma) \ln \left[\left(\frac{\beta(1-\gamma)}{\gamma+\beta(1-\gamma)}\right)^{\beta} h_{t}\left(1-v n_{t}\right)^{\beta}\left(n_{t} q\right)^{(1-\beta)}\right] \\
& \left.-\frac{(1-\gamma)(1-\beta)(1-q)}{2 n_{t} q}\right\},
\end{aligned}
$$

subject to: $\left(n_{t}\right) \geq 0$.

The first order condition with respect to $n_{t}$ is non-linear,

$$
\frac{-(\gamma+(1-\gamma) \beta) v}{1-v n_{t}}+\frac{(1-\gamma)(1-\beta)}{n_{t}}+\frac{(1-\gamma)(1-\beta)(1-q)}{2 q n_{t}^{2}}=0 .
$$

Proposition 3: When uncertainty is fully incorporated into the parent's optimization problem, an exogenous increase in the survival probability causes them to have fewer children and spend more on the education of each survivor after the uncertainty is resolved.

$$
\begin{aligned}
& \frac{d n_{t}^{*}}{d q}<0, \forall q \\
& \frac{d e_{t}^{*}}{d q}>0, \forall q .
\end{aligned}
$$

Proof: See the Appendix.

Notice that introducing uncertainty is the sufficient condition to alter the results that are given in Proposition 1. In fact in this simple and general setup of two periods, where parents only make fertility, education, and consumption choices and where expected number of survivors are given by $n_{t} q$, I would argue that uncertainty is the necessary condition to get the results of Proposition $3 .{ }^{17}$ Another necessary condition to get the positive effect of the survival probability on the optimal amount of education is the linearity of the optimal fertility rate in the survival probability. Using a linear approximation of $d n / d q$ implies $d^{2} n / d q^{2}=0$. In fact $d^{2} n / d q^{2}>0$ and with a high value for $\beta$ it goes to zero. Thus the result holds to a first degree approximation or alternatively it depends on $\beta$ being close to $1 .{ }^{18}$ Most of the related literature assumes a linear human capital production function, i.e.,

\footnotetext{
${ }^{16}$ See Kalemli-Ozcan (2003) for details of the Delta Method.

${ }^{17}$ Recall that results of Proposition 1 holds for different functional forms. One can always introduce a bequest motive, more periods for retirement, and sequential fertility, all of which may or may not be sufficient conditions and may alter the results. See Kalemli-Ozcan (2000) for more details and a survey of these type of models and their specific conditions. See also Lorentzen et al. (2004) for an excellent survey of this literature.

${ }^{18}$ See Appendix for details.
} 
assumes very high returns to education $(\beta=1)$. Also Parente and Prescott $(2000)$ argue that when $\beta$ is close to 1 , the differences in the time allocated to human capital investment lead to large differences in the steady state levels of income per capita, which are consistent with the data.

This model is also consistent with the facts of the demographic transition.

Proposition 4: Under uncertainty, at low levels of survival $(q \rightarrow 0)$, an increase in the survival probability unambiguously raises the population growth rate, while at high levels of survival $(q \rightarrow 1)$ an increase in the survival probability causes the population growth rate to decline if the returns to education are high enough $(\beta \rightarrow 1)$.

$$
\begin{aligned}
& \frac{d E_{t}\left(N_{t}^{*}\right)}{d q}>0 \quad \text { if } q \rightarrow 0, \\
& \frac{d E_{t}\left(N_{t}^{*}\right)}{d q}<0 \quad \text { if } q \rightarrow 1 \text { and } \beta \rightarrow 1,
\end{aligned}
$$

where $\frac{d^{2} E_{t}\left(N_{t}^{*}\right)}{d q^{2}}<0$.

Proof: See the Appendix.

\section{Assessing Quantitative Magnitudes}

I consider a different form of uncertainty in this paper than the one in Kalemli-Ozcan (2003). This paper specifically asks whether or not infant or child mortality will have an effect on human capital investment decision of parents even though parents invest only in the human capital of surviving children. Thus in the setup of the current paper fertility and the human capital investment decisions are not simultaneous, where the former takes place before the uncertainty about mortality is resolved and the latter takes place after the uncertainty is resolved. On the other hand, Kalemli-Ozcan (2003) focuses on a decision making environment, where fertility and human capital investment decisions are made simultaneously before the uncertainty about mortality is resolved.

From an empirical perspective these two cases can also be interpreted as follows: Which mortality does matter most for human capital investment, before age 5 or after age 5 , such as age 15 ? I will try to answer this question in this section. This is important since if infant mortality and mortality at later ages are highly correlated, then there is another competing hypothesis that why infant mortality rate could be important in affecting human capital investment. This is simply due to a signalling effect. Declining infant mortality could signal to parents of surviving children (aged 5 to 15), that investment in human capital of these children has become safer. The current setup so far cannot differentiate between the two hypothesis, i.e., whether or not infant mortality matter on its own or via it's signalling effect for the mortality at later ages. ${ }^{19}$ This section is aimed at answering this question.

\footnotetext{
${ }^{19}$ I am grateful to the referee for pointing this out.
} 
I solve for the optimal values of the endogenous variables using age-specific survival data from Sweden for the parameter $q$. I consider the changes in the survival probabilities from 1880 to 1980 for Sweden. Survival probability at age $5, q_{5}$, increased from 0.80 to 0.99 , whereas survival probability at age $15, q_{5}$, increased from 0.75 to 0.99 during this period. The corresponding change in $e$ is 63 percent if I use the survival probability at age 5 and 68 percent if I use the survival probability at age 15 . Thus when each case happens one at a time, the impact on human capital investment is comparable. According to the model, if only infant survival improves human capital investment increases 63 percent and if only age 15 survival improves human capital investment increases 68 percent. As a result the model implies that both age 5 and age 15 mortality have independent effects.

\section{Conclusion}

Empirical studies show that there is a significant positive effect of human capital investment and a negative effect of fertility on economic development. Furthermore, researchers find a positive correlation between life expectancy (or health proxies) and the rate of economic growth. However, we still do not have any direct evidence regarding the mechanism through which higher life expectancy promotes growth. The models on the issue have been limited so far. One reason for the limited theoretical analysis is the argument that since most of the mortality decline occurred in infancy, mortality should not affect the human capital investment decision, which comes later in life. Hence the "human capital investment" mechanism cannot be one of the channels through which increased life expectancy promotes growth. This paper belongs to the line of research that argues the contrary.

I examine the effects of mortality decline on fertility and human capital investment decision of parents taking into account the uncertainty about the number of surviving children. The uncertainty implies parents can choose between two different strategies regarding the timing of the educational investment. Education may be provided before or after uncertainty about child survival is realized. This paper presents a model that shows mortality decline causes educational investment to increase even parents choose to invest only in human capital of their surviving children. As a result of an exogenous decline in mortality, parents decrease their precautionary demand for children, freeing up previously wasted resources for investment in surviving children. Thus mortality decline can promote growth regardless of the timing of the educational investment. In addition the model is consistent with the facts of demographic transition, mainly the hump-shaped relation between the population growth and the survival probability, implying mortality decline can be one of the mechanisms that triggers the demographic transition.

\section{Appendix A}

\section{Proof of Proposition 3:}


Multiplying everywhere in the equation (17) by $n_{t}^{2}$ gives

$$
G G\left(n_{t}, q\right)=\frac{-(\gamma+(1-\gamma) \beta) v n_{t}^{2}}{1-v n_{t}}+(1-\gamma)(1-\beta) n_{t}+\frac{(1-\gamma)(1-\beta)(1-q)}{2 q}=0,
$$

which defines $n_{t}^{*}$ implicitly. Thus, suppressing $*$ and $t$ subscript for convenience and using subscripts for partial derivatives from now on

$$
\frac{d n}{d q}=-\frac{G G_{g}}{G G_{n}}
$$

Equation (20) can also be written as

$$
\frac{(1-\gamma)(1-\beta)(1-q)}{2 q}=\frac{(\gamma+(1-\gamma) \beta) v n^{2}}{1-v n}-(1-\gamma)(1-\beta) n .
$$

Thus, LHS of the equation (22) is only a function of $q$ and RHS of it is only a function of $n$.

$$
\begin{aligned}
L H S_{q}(q) & =G G_{g}, \\
R H S_{n}(n) & =-G G_{n} .
\end{aligned}
$$

Given $0<q \leq 1$, it is easy to show that $\operatorname{LHS}(q)$ is always negative

$$
\begin{aligned}
L H S_{q}(q) & =-\frac{(1-\gamma)(1-\beta)}{2 q^{2}}<0 \forall q, \\
L H S_{q q}(q) & =\frac{(1-\gamma)(1-\beta)}{q^{3}}>0 \forall q, \\
\lim _{q \rightarrow 0} L H S(q) & \rightarrow+\infty \\
\lim _{q \rightarrow 1} L H S(q) & =0 .
\end{aligned}
$$

Thus equation (24) implies

$$
G G_{q}<0 \forall q
$$

Given $0 \leq n \leq \frac{1}{v}$, it is easy to show that $\operatorname{RHS}(n)$ is always positive for the range of optimal $\mathrm{n}$. $R H S(n)$ can be written as

$$
R H S(n)=\frac{n(v n-(1-\gamma)(1-\beta))}{(1-v n)}
$$

Taking the derivative with respect to $n$ gives 


$$
R H S_{n}(n)=\frac{v n(2-v n)-(1-\gamma)(1-\beta)}{(1-v n)^{2}} .
$$

To determine the sign of equation (27), one has to evaluate the following:

$$
\begin{aligned}
\lim _{n \rightarrow 0} R H S_{n}(n) & =-(1-\gamma)(1-\beta)<0, \\
\lim _{n \rightarrow 1 / v} R H S_{n}(n) & \rightarrow+\infty, \\
R H S_{n n}(n) & =\frac{2 v(\gamma+\beta(1-\gamma))}{(1-v n)^{3}}>0 \forall n, \\
\lim _{n \rightarrow 0} R H S(n) & =0 . \\
\lim _{n \rightarrow 1 / v} R H S(n) & \rightarrow+\infty .
\end{aligned}
$$

Thus equation (28) implies ${ }^{20}$

$$
-G G_{n}>0 \forall n \text {. }
$$

Therefore equations (25) and (29) together with the equation (21) imply

$$
\frac{d n^{*}}{d q}<0
$$

which is the first part of the proof of Proposition 3.

For the second part of the proof, we must show $d e_{t}^{*} / d q>0$. This can be written as (suppressing the $*$ and $t$ ),

$$
\frac{d e}{d q}=\frac{\beta(1-\gamma)}{(\beta(1-\gamma)+\gamma) n q^{2}}\left[-(1-v n)-\frac{d n}{d q} \frac{q}{n}\right]
$$

We can use a linear approximation of $d n / d q$ and thus can write the above equation as

$$
\frac{d e}{d q}=\frac{\beta(1-\gamma)(\beta(1-\gamma)+\gamma) v}{(1-q(\beta(1-\gamma)+\gamma))^{2}}>0 \forall q
$$

Note that using a linear approximation of $d n / d q$ implies $d^{2} n / d q^{2}=0$. In fact $d^{2} n / d q^{2}>0$ and with a high $\beta$ it goes to to zero. Thus the result in equation (32) holds for a first degree approximation or it depends on $\beta$ being close to 1 .

\section{Proof of Proposition 4:}

Substituting $n_{t}=E\left(N_{t}\right) / q$ into the equation (17), suppressing $t$ subscripts gives

$$
\widetilde{G G}(E(N), q)=-2 v E(N)^{2}+(1-\beta)(1-\gamma)[2 q E(N)+(1-q)(q-v E(N)]=0
$$

\footnotetext{
${ }^{20}$ Note that $\forall n$ here describes the range of $n$ 's such that there can be a solution to the optimization problem.
} 
which defines $E(N)$ implicitly, thus,

$$
\frac{d E(N)}{d q}=-\frac{\widetilde{G G}_{q}}{\widetilde{G G}_{E(N)}} .
$$

Evaluating this with implicit function theorem gives

$$
\frac{d E(N)}{d q}=\frac{(1-\gamma)(1-\beta)[(2+v) E(N)+1-2 q]}{4 v E(N)-(1-\gamma)(1-\beta)[(2+v) q-v]} .
$$

Thus when $q \rightarrow 0, E(N) \rightarrow 0$ and $n \rightarrow 1 / v$. Hence, equation (35) is unambiguously positive

$$
\frac{d E(N)}{d q}=\frac{1}{v}>0 \text { if } q \rightarrow 0 .
$$

When $q \rightarrow 1, E(N) \rightarrow n$ and $n \rightarrow(1-\gamma)(1-\beta) / v$. Hence, equation (35) is ambiguous

$$
\frac{d E(N)}{d q}=\frac{(1-\gamma)(1-\beta)[(2+v) n-1]}{4 v n-2(1-\gamma)(1-\beta)}<0 \text { if } q \rightarrow 1 \text { and } \beta \rightarrow 1
$$

Substituting $n \rightarrow(1-\gamma)(1-\beta) / v$, gives us the necessary condition for the equation (37) to be negative

$$
\frac{(1-\gamma)(1-\beta)}{v}<\frac{1}{2+v} .
$$

If $\beta \rightarrow 1$, the condition in equation (38) is satisfied. So $\beta \rightarrow 1$ is the sufficient condition.

\section{Proof of Concavity:}

Showing $\frac{d^{2} E_{t}\left(N_{t}^{*}\right)}{d q^{2}}<0$ is straightforward. This can be written as

$$
\frac{d^{2} E_{t}\left(N_{t}^{*}\right)}{d q^{2}}=\frac{G G_{n n}\left(G G_{q}\right)^{2} q}{\left(-G G_{n}\right)^{3}}+\frac{q G G_{q q}}{-G G_{n}}+\frac{2 G G_{q}}{-G G_{n}} .
$$

But $q G G_{q q}=-2 G G_{q}$, thus this implies

$$
\frac{d^{2} E_{t}\left(N_{t}^{*}\right)}{d q^{2}}=\frac{G G_{n n}\left(G G_{q}\right)^{2} q}{\left(-G G_{n}\right)^{3}}<0 \forall q
$$

Equation (40) holds given the fact that $-G G_{n}>0$ and $-G G_{n n}>0$. 


\section{References}

Becker, G. S., Barro, R. J., (1988). "A Reformulation of the Economic Theory of Fertility," Quarterly Journal of Economics 103, 1-25.

Boldrin, Michele and Larry E. Jones (2002). "Mortality, Fertility, and Saving in a Malthusian Economy," Review of Economic Dynamics, vol. 5, no. 4, pp. 775-814.

Chakraborty, Shankha (2004). "Endogenous Lifetime and Economic Growth," Journal of Economic Theory, vol. 116.

Cigno, Alessandro (1998). "Fertility Decisions when Infant Survival is Endogenous," Journal of Population Economics, 11, 21-28.

Eckstein, Z., Mira, P., Wolpin, K.I., (1998). "A Quantitative Analysis of Swedish Fertility Dynamics: 1751-1990," CEPR Discussion Paper 1832.

Doepke, Matthias (2004). "Child Mortality and Fertility Decline: Does the Barro-Becker Model Fit the Facts?" Journal of Population Economics, forthcoming.

Galor, Oded (2005). "The Demographic Transition and the Emergence of Sustained Economic Growth" Journal of European Economic Association, forthcoming.

Ehrlich, I., Lui, F. T., (1991). "Intergenerational Trade, Longevity, Intrafamily Transfers and Economic Growth," Journal of Political Economy 99, 1029-1059.

Kalemli-Ozcan, S. (2000). "Uncertainty and Economic Growth," PhD. Dissertation, Brown University.

Kalemli-Ozcan, S. (2002). "Does Mortality Decline Promote Economic Growth?," Journal of Economic Growth 7.

Kalemli-Ozcan, S., (2003). "A Stochastic Model of Mortality, Fertility and Human Capital Investment," Journal of Development Economics, 62.

Kalemli-Ozcan, S., H. Ryder, and D. N. Weil (2000). "Mortality Decline, Human Capital Investment and Economic Growth," Journal of Development Economics, 62.

Keyfitz, N., W. Flieger. (1968). World Population: An Analysis of Vital Data. Chicago: The University of Chicago Press.

Keyfitz, N., W. Flieger. (1990). World Population Growth and Aging. Chicago: The University of Chicago Press. 
Livi-Bacci, M., (1997). A Concise History of World Population. Oxford, UK.

Lorentzen, P., J. McMillan, and R. Wacziarg (2004). "Death and Development," mimeo, Stanford University.

Matthews, R.C.O, Feinstein, C. H., Odling-Smee. J. C., (1982). British Economic Growth, 1856-1973. Stanford, CA.

Meltzer, D., (1992). "Mortality Decline, the Demographic Transition and Economic Growth," Ph.D Dissertation, University of Chicago.

Parente S. L., and E. C. Prescott. (2000). Barriers to Riches. Cambridge: MIT Press.

Ram, R. and T. Schultz, (1979). "Life Span, Health, Savings and Productivity," Economic Development and Cultural Change 13, 399-421.

Sah, R. K., (1991). "The Effects of Child Mortality Changes on Fertility Choice and Parental Welfare," Journal of Political Economy 99, 582-606.

Schultz, P. T. (1997). "Demand for Children in Low Income Countries." In Mark R. Rosenzweig and Oded Stark (eds), Handbook of Population and Family Economics. Amsterdam: Elsevier Science.

Soares, Rodrigo P (2004). "Mortality Reductions, Educational Attainment, and Fertility Choice," American Economic Review, forthcoming.

Strulik, Holger (2003). "Mortality, the Trade-Off between Child Quality and Quantity, and DemoEconomic Development," Metroeconomica, 54:4, 499-520.

Strulik, Holger (2004). "Child Mortality, Child Labor and Economic Development," Economic Journal, 114, 547-568.

Wolpin, Kenneth I. (1997), "Determinants and Consequences of the Mortality and Health of Infants and Children," in: Mark R. Rosenzweig and Oded Stark, eds., Handbook of Population and Family Economics, Volume 1A, Amsterdam, Netherlands: Elsevier Science. 


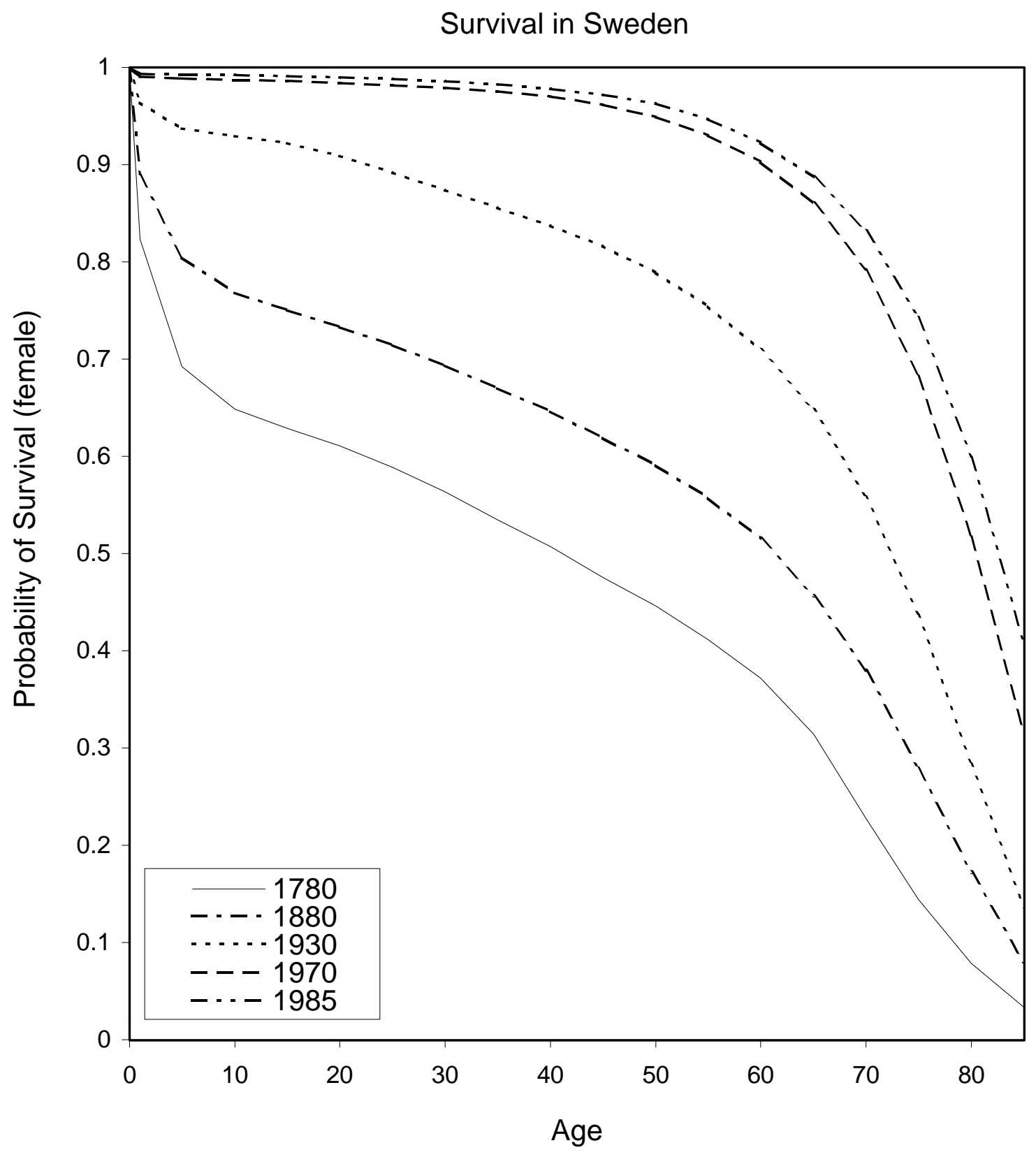

Figure 1: Mortality in Sweden

Notes: The survival function shows the probability that a person will be alive at a given age. Life expectancy at birth is the area under the survival function. Swedish data is from Keyfitz and Flieger (1968, 1990). 